University of Nebraska - Lincoln

DigitalCommons@University of Nebraska - Lincoln

$11-15-2007$

\title{
Myricetin inhibits Escherichia coli DnaB helicase but not primase
}

\author{
Mark A. Griep \\ University of Nebraska-Lincoln, mgriep1@unl.edu \\ Sheldon Blood \\ University of Nebraska - Lincoln \\ Marilynn A. Larson \\ University of Nebraska Medical Center, Omaha, Nebraska \\ Scott A. Koepsell \\ University of Nebraska Medical Center, Omaha, Nebraska \\ Steven $\mathrm{H}$. Hinrichs \\ University of Nebraska Medical Center, shinrich@unmc.edu
}

Follow this and additional works at: https://digitalcommons.unl.edu/chemistrygriep

Part of the Chemistry Commons

Griep, Mark A.; Blood, Sheldon; Larson, Marilynn A.; Koepsell, Scott A.; and Hinrichs, Steven H., "Myricetin inhibits Escherichia coli DnaB helicase but not primase" (2007). Mark Griep Publications. 4.

https://digitalcommons.unl.edu/chemistrygriep/4

This Article is brought to you for free and open access by the Published Research - Department of Chemistry at DigitalCommons@University of Nebraska - Lincoln. It has been accepted for inclusion in Mark Griep Publications by an authorized administrator of DigitalCommons@University of Nebraska - Lincoln. 
Published in Bioorganic \& Medicinal Chemistry 15:22 (November 15, 2007), pp. 7203-7208; doi:10.1016/j.bmc.2007.07.057

Copyright (C) 2007 Elsevier Ltd. Used by permission. http://www.sciencedirect.com/science/journal/09680896

Submitted April 3, 2007; revised June 29, 2007; accepted July 3, 2007; published online August 26, 2007.

\title{
Myricetin inhibits Escherichia coli DnaB helicase but not primase
}

\author{
Mark A. Griep ${ }^{\mathrm{a}, \mathrm{c}, *}$, Sheldon Blood ${ }^{\mathrm{a}}$, Marilynn A. Larson ${ }^{\mathrm{b}, \mathrm{c}}$, \\ Scott A. Koepsell ${ }^{\text {b, c }}$, and Steven H. Hinrichs ${ }^{\text {b, }}$ c \\ ${ }^{a}$ Department of Chemistry, University of Nebraska-Lincoln, 614 Hamilton Hall, Lincoln, NE 68588-0304, USA \\ ${ }^{b}$ Department of Microbiology and Pathology, University of Nebraska Medical Center, Omaha, NE 68198, USA \\ ${ }^{c}$ Nebraska Center for Biosecurity, University of Nebraska Medical Center, Omaha, NE 68198, USA \\ *Corresponding author: tel: 402 472-3429; fax: 402 472-9402; email: mgriep1@unl.edu
}

\begin{abstract}
Primase and DnaB helicase play central roles during DNA replication initiation and elongation. Both enzymes are drug targets because they are essential, persistent among bacterial genomes, and have different sequences than their eukaryotic equivalents. Myricetin is a ubiquitous natural product in plants that is known to inhibit a variety of DNA polymerases, RNA polymerases, reverse transcriptases, and telomerases in addition being able to inhibit kinases and helicases. We have shown that myricetin inhibits Escherichia coli DnaB helicase according to a mechanism dominated by noncompetitive behavior with a $K_{\mathrm{i}}$ of $10.0 \pm 0.5 \mu \mathrm{M}$. At physiological ATP concentration, myricetin inhibits $E$. coli DnaB helicase with an inhibitory concentration at $50 \%$ maximal $\left(\mathrm{IC}_{50}\right)$ of $11.3 \pm 1.6 \mu \mathrm{M}$. In contrast, myricetin inhibited E. coli primase at least 60 fold weaker than DnaB helicase and far weaker than any other polymerase.
\end{abstract}

Keywords: Myricetin, DNA replication, DnaB helicase, Primase, Escherichia coli

Abbreviations: ssDNA $=$ single-stranded DNA

\section{Introduction}

Helicase and primase are required during DNA replication because DNA is an antiparallel duplex and because no replicative DNA polymerase is able to initiate polymers de novo. Primase is a specialized DNA-dependent RNA polymerase that generates short oligoribonucleotide polymers de novo that can be elongated by DNA polymerase. ${ }^{1,2}$ During DNA replication, primase initiates the leading strand synthesis at least once and the lagging strand synthesis many times. Even though all autonomous life forms store their genetic information in duplex DNA and use a primase to initiate leading and lagging strand DNA synthesis, the primases from archaea and eukaryotes are structurally unrelated to the primases from prokaryotes. ${ }^{3,4}$ In Escherichia coli, conditionally lethal mutations in the primase gene yield lethal phenotypes under the non-permissive conditions, demonstrating the essentiality of the enzyme. ${ }^{5,6}$ The indispensable function of primase and the structural divergence of the eukaryotic and prokaryotic primases have led to the identification of the enzyme as a target for novel antibiotic development. ${ }^{7,8}$
The DnaG protein from E. coli is the model eubacterial primase because its structure and function have been extensively characterized. It has been demonstrated that E. coli DnaG primase is slow, binds ssDNA as a dimer, and that interaction with DnaB helicase stimulates its catalytic activity over 15 -fold. ${ }^{9-12}$ E. coli DnaG primase specifically initiates RNA primer synthesis complementary to the trinucleotide $5^{\prime}-\mathrm{d}(\mathrm{CTG})-3^{\prime}$ in vitro, and E. coli Okazaki fragment initiation maps to a $\mathrm{d}(\mathrm{CTG})$ on the chromosomal template strand in vivo. ${ }^{13,14}$

DnaB helicase from E. coli is the model eubacterial helicase that unwinds duplex DNA at the replication fork so that the two strands can be replicated by the combination of primase and DNA polymerase. ${ }^{15}$ In E. coli, conditionally lethal mutations in the $d n a B$ gene yielded lethal phenotypes under the non-permissive conditions, demonstrating the essentiality of the gene product for replication elongation and initiation. ${ }^{16-}$ ${ }^{20}$ During the initiation phase of replication, E. coli DnaB helicase interacts with DnaA origin-binding protein, DnaC helicase loading protein, and primase. ${ }^{21,22}$ During the elongation phase, dimeric DNA polymerase III is tethered to the helicase 

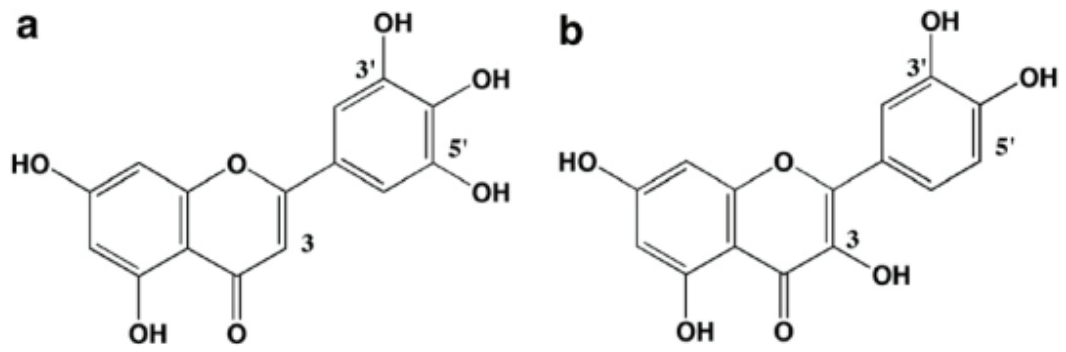

Figure 1. The structures of (a) myricetin and (b) quercetin differ with regard to the hydroxyls on carbons 3 and $5^{\prime}$. Tests with a variety of flavonoids revealed that the $3^{\prime}$ and $5^{\prime}$ hydroxyls of myricetin were very important for its ability to inhibit RSF1010 RepA helicase better than the other flavonoids. ${ }^{57}$

via its tau subunit and primase repeatedly and transiently interacts with the helicase to initiate lagging strand synthesis. ${ }^{23}$, 24 During the termination phase, the replication machinery is prevented from over-replicating the genome by the inhibitory interaction between the Tus protein and DnaB helicase. ${ }^{25}$ As the central hub of the replication machinery and given the structural divergence of the eukaryotic and prokaryotic fork helicases, DnaB is considered to be a novel target for antibiotic development.

High-throughput assays have been developed for helicase activity, primase activity, and helicase-stimulated primase activity to identify novel inhibitors of these two enzymes. ${ }^{7,26-}$ ${ }^{28}$ Primase activity assays have been used to identify several natural product inhibitors, such as a bicyclic macrolide, two phenolic saccharides, and a group of synthetic compounds identified from a series of virtual and real screens. ${ }^{8,29,30}$ The phenolic saccharides are not good leads because they inhibit primase activity through their ability to bind to ssDNA and thereby occlude primase. Helicase activity assays have identified inhibitors from among the known families of flavonols and triaminotriazines. ${ }^{31,32}$ These families of compounds inhibit many helicases and/or kinases. ${ }^{31-33}$

Flavonoids provide flavor and color to all parts of plants. Over 5,000 different flavonoids, including myricetin and quercetin (Figure 1), have been described and some of them have been tested for biological activity. ${ }^{34}$ Many flavonoids have anti-carcinogenic and antibacterial activities but the sites of action are known for only a few. ${ }^{35}$ One of the exceptions is that quercetin's antimicrobial activity can be attributed in part to its inhibition of gyrase. Myricetin has been shown to have antimicrobial activity but it has not been possible to attribute its effect to any one target. Determining its target has been difficult because flavonoids tend to aggregate, adhere to the container surface, and immobilize the enzyme being assayed so that it is inactivated by a nondrug-like mechanism. ${ }^{36,37}$ Nevertheless, careful analysis has shown that myricetin and quercetin inhibit a variety of DNA polymerases, RNA polymerases, reverse transcriptases, and telomerases. ${ }^{38-41}$

In the present study, it was discovered that DnaB helicase activity was 60 times more sensitive to myricetin than was primase activity. In fact, primase was the least myricetin-sensitive of all polymerases tested so far. The myricetin inhibition kinetics of the DnaB ATPase activity were consis- tent with simple noncompetitive inhibition with physiological amounts of the substrate ATP.

\section{Results}

The purpose of this study was to determine the extent to which myricetin was capable of inhibiting $E$. coli DnaB helicase, primase, and DnaB-stimulated primase activity. The results showed that DnaB helicase was much more sensitive to myricetin than was primase.

\subsection{Myricetin inhibition of DnaB ATPase activity}

After some preliminary experiments to establish the best range of concentrations, the inhibition of DnaB ATPase activity was analyzed as a function of ATP and myricetin. In the absence of myricetin (Figure 2a and b), the ATP concentration dependence exhibited hyperbolic saturation kinetics with a $K_{\mathrm{M}}$ of $31 \mu \mathrm{M}$ ATP and $V_{\max }=2870 \mathrm{nM} / \mathrm{s}$ (Table 1). These were similar to reported values. ${ }^{42,}{ }^{43}$ Hyperbolic kinetics indicated that all of the ATP active sites were equal and noninteracting even though the enzyme has six identical subunits per functional complex. As the myricetin was increased to $12 \mu \mathrm{M}$, the apparent $V_{\max }$ decreased 2.7 -fold whereas the apparent $K_{\mathrm{M}}$ decreased 11-fold. The decrease in the apparent $K_{\mathrm{M}}$ was not consistent with competition between ATP and myricetin for the active site. Simple competitive inhibition would have increased the $K_{\mathrm{M}}$ according to the relationship of $K_{\mathrm{M}}^{\prime}=K_{\mathrm{M}}\left(1+[\mathrm{I}] / K_{\mathrm{i}}\right)$, where $K_{\mathrm{M}}^{\prime}$ is the apparent $K_{\mathrm{M}}$ and $K_{\mathrm{i}}$ is the median inhibition concentration. When myricetin was increased to $30 \mu \mathrm{M}$, the apparent $K_{\mathrm{M}}$ and apparent $V_{\text {max }}$ decreased by about the same amount indicating that the kinetic affinity for ATP was no longer being so dramatically affected. Higher myricetin concentration led to a continued decrease in apparent $V_{\max }$ but an increase in the apparent $K_{\mathrm{M}}$, which was finally consistent with some small degree of competitive inhibition.

The decrease in apparent $V_{\max }$ suggested that it may be due to noncompetitive inhibition, in which the inhibitor is able to bind to both the free enzyme and the enzyme-substrate complex to create a "dead end" complex that is inactive. Simple noncompetitive inhibition decreases the $V_{\max }$ according to the relationship of $V_{\text {max }}^{\prime}=V_{\max } /\left(1+[\mathrm{I}] / K_{\mathrm{i}}\right)$, where $V_{\text {max }}^{\prime}$ is the apparent $V_{\max }$ and $K_{\mathrm{i}}$ is the median inhibition concentration. 

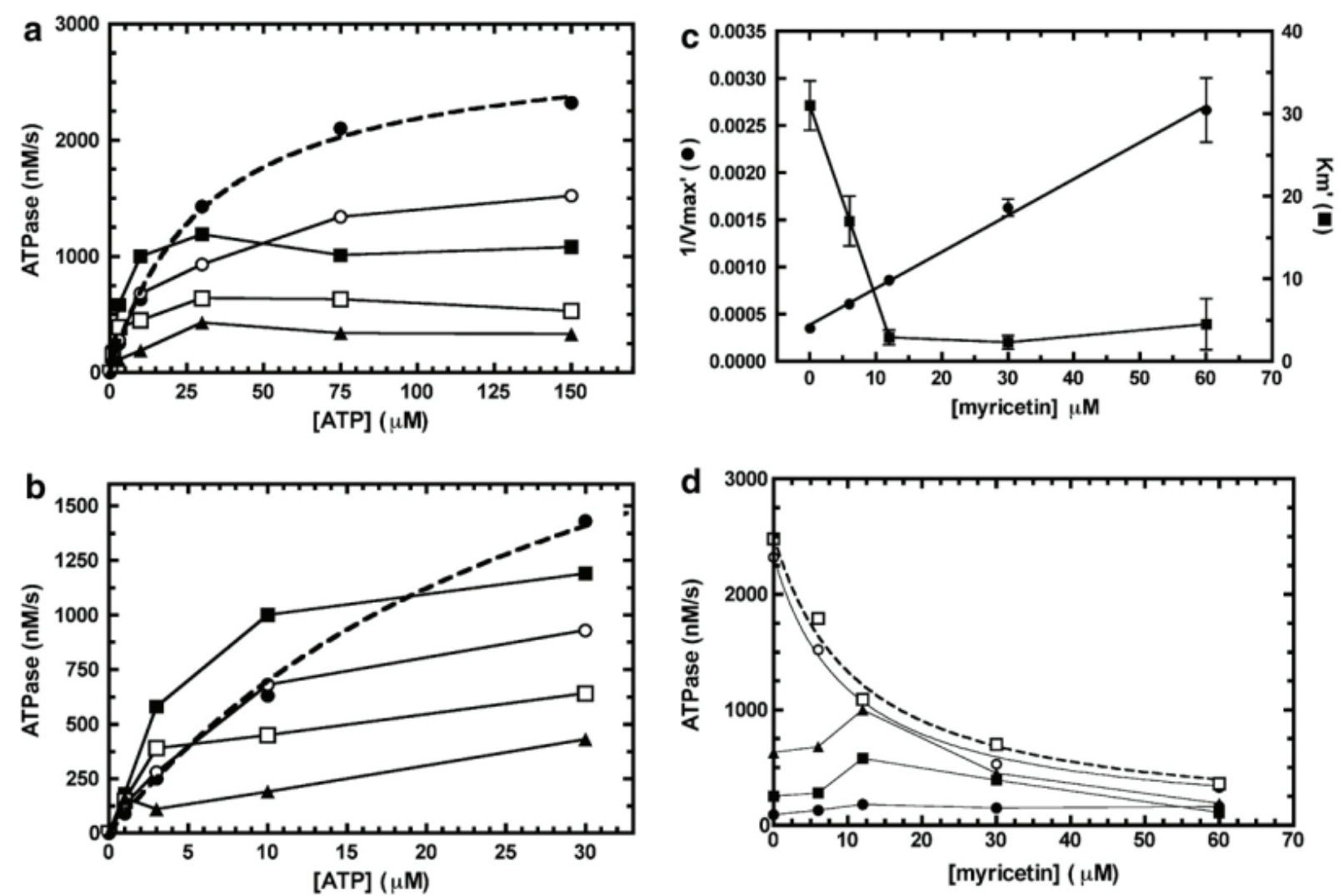

Figure 2. The effect of ATP and myricetin on E. coli DnaB ATPase. In panels a and b, the myricetin concentrations were $0 \mu \mathrm{M}(\bullet), 6(\circ), 12(\bullet), 30(\square)$, and 60 $(\boldsymbol{\Lambda})$. In panel c, apparent kinetic constants from the data were plotted versus myricetin concentration. In panel d, the ATPase activity was replotted versus myric-

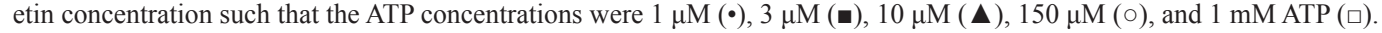

Table 1. Apparent Michaelis-Menten constants for E. coli DnaB helicase in the presence of myricetin

\begin{tabular}{llll}
\hline Myricetin $(\boldsymbol{\mu M})$ & $\boldsymbol{V}_{\text {max }}^{\prime}(\boldsymbol{\mu M} / \mathbf{s})$ & $\left.\boldsymbol{K}_{\mathbf{M}}{ }^{(} \boldsymbol{\mu M}\right)$ & $\boldsymbol{R}^{2}$ \\
\hline 0 & $2.87 \pm 0.09$ & $31 \pm 3$ & 0.998 \\
6 & $1.64 \pm 0.08$ & $17 \pm 3$ & 0.989 \\
12 & $1.06 \pm 0.07$ & $2.9 \pm 0.9$ & 0.958 \\
30 & $0.61 \pm 0.04$ & $2.3 \pm 0.8$ & 0.952 \\
60 & $0.35 \pm 0.05$ & $4.5 \pm 3.1$ & 0.801 \\
\hline
\end{tabular}

The mathematical inversion of this equation $\left(1 / V^{\prime}{ }_{\max }=1 /\right.$ $V_{\max } /\left(1+[\mathrm{I}] / K_{\mathrm{j}}\right)$ indicates that a plot of $1 / V^{\prime}{ }_{\max }$ versus $[\mathrm{I}]$ will be linear if it conforms to noncompetitive inhibition and that the slope and $y$-intercept can be used to determine the inhibition constant. When the data were so plotted, they yielded a linear relationship (Figure $2 \mathrm{c}$ circles) and a $K_{\mathrm{i}}$ of $10.0 \pm 0.5 \mu \mathrm{M}$. Therefore, the decrease in enzyme activity as a function of myricetin at saturating ATP was due to noncompetitive inhibition.

To determine the inhibitor concentration that causes $50 \%$ inhibition, $\mathrm{IC}_{50}$, the ATPase activity was replotted versus myricetin concentration (Figure 2d). At the highest ATP concentrations, $150 \mu \mathrm{M}$ (solid line) and $1 \mathrm{mM}$ (dashed line), the data conformed to the inhibition equation: \% activity $=Y_{\max }-Y_{\max }[\mathrm{I}] /\left(\mathrm{IC}_{50}+[\mathrm{I}]\right)$. Fitting the $150 \mu \mathrm{M}$ ATP data revealed that the $Y_{\max }$ was $2340 \pm 50 \mathrm{nM} / \mathrm{s}$ and $\mathrm{IC}_{50}$ was
$10.2 \pm 0.6 \mu \mathrm{M}$ myricetin with an $R^{2}$ of 0.997 . At $1 \mathrm{mM}$ ATP, the $Y_{\max }$ was $2510 \pm 110 \mathrm{nM} / \mathrm{s}$ and $\mathrm{IC}_{50}$ was $11.3 \pm 1.6 \mu \mathrm{M}$ myricetin with an $R^{2}$ of 0.986 . These values were statistically the same as the $K_{\mathrm{i}}$, showing that the dominant inhibition mechanism at high and saturating ATP was noncompetitive. An examination of the myricetin effect (Figure 2d) further showed that myricetin stimulated ATPase when its concentration was less than $12 \mu \mathrm{M}$ and the ATP concentration was less than $10 \mu \mathrm{M}$. At these low non-physiological ATP concentrations (Figure 2d), the $K_{\mathrm{M}}$ effects (Figure 2c) indicate that myricetin binding to non-active sites was able to enhance ATPase activity by increasing the enzyme's kinetic affinity for ATP more than its $V_{\max }$ decreases.

\subsection{Myricetin inhibition of primase alone}

The ability of myricetin to inhibit primase activity in the absence of DnaB was tested because it is an inhibitor of a variety of DNA polymerases, RNA polymerases, and reverse transcriptases. ${ }^{38-41}$ This was also an important control for the more physiologically relevant reaction of DnaB-stimulated primer synthesis. When myricetin was added to the reaction containing primase and its substrates, it barely inhibited in a concentration-dependent manner (Figure 3). It was not possible to test higher myricetin concentrations due to myricetin's low solubility. Even though the error in each measurement is about $5 \%$, the same scale as the effect, fitting of the data to the 


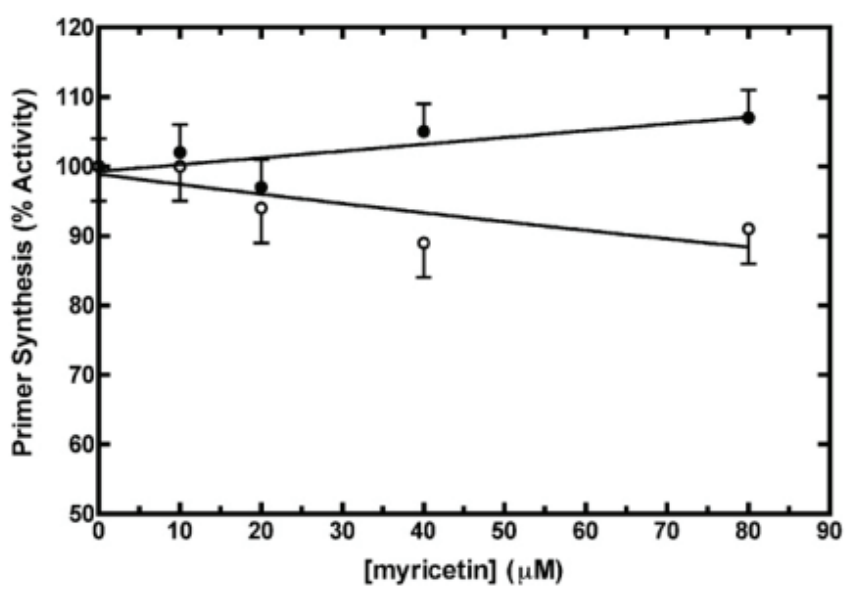

Figure 3. The effect of myricetin on $E$. coli primase activity in the presence $(\bullet)$ and absence ( $\circ$ ) of E. coli DnaB helicase. Each data set was normalized to the number of primers synthesized in the absence of myricetin. In the absence of helicase, primase activity was weakly inhibited and poorly fit but the constants were $Y_{\max }=99 \pm 2 \%, \mathrm{IC}_{50}=700 \pm 300 \mu \mathrm{M}$ myricetin, and an $R^{2}$ of 0.634 . DnaB-stimulated primer synthesis could not be fit to a hyperbolic relationship so a line was drawn through the data to show the trend.

inhibition equation revealed that the $\mathrm{IC}_{50}$ was $700 \pm 300 \mu \mathrm{M}$ myricetin. The consequence was that myricetin inhibited primase activity 60 times weaker than it inhibited DnaB ATPase activity and much weaker than the low micromolar $\mathrm{IC}_{50}$ 's for DNA polymerases, RNA polymerases, reverse transcriptases, and telomerases. ${ }^{38-41}$ It may be relevant that the structure of bacterial primase differs from those palm-type nucleic acid polymerases in that it has a 'cashew-shaped' active site shared by no other polymerase family. ${ }^{44,45}$

\subsection{Myricetin inhibition of DnaB-stimulated primer synthesis}

Primase and DnaB stimulate each other's activities. ${ }^{46}$ Of these cross-reactivities, the DnaB stimulation of primer synthesis activity is the most relevant to DNA replication because DNA polymerase cannot synthesize DNA without the resulting primer. Therefore, primer synthesis by primase was measured with and without helicase as a function of myricetin concentration. Unfortunately, the controls without myricetin but with DMSO showed that $0.5-4 \%$ DMSO, which would be added with 10-40 $\mu \mathrm{M}$ myricetin as its solvent, completely inhibited the helicase stimulation when it was present at its most stimulatory ratio relative to the primase. ${ }^{12,13,46}$ This reduced level of primase activity was the same as primase alone and may reflect a slight stimulation effect by the myricetin (Figure 3 ). Therefore, DMSO may not cause primase and helicase to dissociate from each other, but rather the presence of helicase may alter the ability of primase to be inhibited by myricetin.

\section{Discussion}

Myricetin is one of the six major flavonoids, plant pigments found in many foods and beverages, that are nutrition- ally interesting primarily for their antioxidant activities. ${ }^{47} \mathrm{We}$ show here that myricetin inhibits homohexameric E. coli DnaB with a $K_{\mathrm{i}}$ and $\mathrm{IC}_{50}$ of about $10 \mu \mathrm{M}$. The results also showed that myricetin would be an effective inhibitor at the log-phasegrowth-phase ATP concentration of $3 \mathrm{mM}^{48}$ The inhibitory mechanism was noncompetitive, indicating that myricetin does not bind to the active site. Even though the mechanism for ATP hydrolysis by hexameric helicases is complex, the current model for DnaB is that ATP can bind and be hydrolyzed in the active site of every other subunit. ${ }^{49}$ Binding of ATP to the remaining three subunits is weaker and negatively cooperative. ${ }^{50}$ For these reasons, it is interesting to speculate that myricetin is binding to the unfilled active sites to shut down the hydrolytic activity of the ATP-bound active sites.

The unwinding mechanism of the $\mathrm{T} 7$ gene 4 protein, a DnaB homolog, has been proposed to pass ssDNA from one subunit to another within the toroid as each adjacent subunit binds ATP, hydrolyzes it, and then releases ADP and phosphate. ${ }^{51}$ When myricetin concentration is low, it must bind at or near the ATP pocket of one subunit such that it stimulates ATP synthesis in adjacent subunits. When myricetin concentration is moderate or high, it must bind to more than one subunit to lock the homohexamer into an inactive complex.

Other studies have shown that myricetin inhibited RSF1010 RepA, a distant hexameric helicase homolog, with a $K_{\mathrm{i}}=23 \mu \mathrm{M}$ and $\mathrm{IC}_{50}=50 \mu \mathrm{M}$. $^{31}$ This is substantially weaker than the inhibition of DnaB helicase described here. The RepA myricetin inhibition kinetics also differed from those with DnaB in that they were competitive. Nevertheless, of the several flavonoids this group tested, myricetin was the most effective at inhibiting cellular growth. The minimal inhibitory concentration for E. coli was $0.50 \mathrm{mg} / \mathrm{mL}$ and for Bacillus subtilis was $0.25 \mathrm{mg} / \mathrm{mL} .^{31}$

RSF1010 RepA differs from both bacterial DnaB and $\mathrm{T} 7$ gene 4 protein in that it lacks a distinct N-terminal domain. ${ }^{52,53}$ Specifically, DnaB is composed of three domains: the N-terminal domain (NTD or DnaB $\alpha$ ), the ATPase shoulder $(\mathrm{DnaB} \beta)$, and the $\mathrm{C}$-terminal hexamerization domain (DnaB $\gamma)$. Bacterial primase binds to the linker that connects the DnaB NTD with its ATPase domain. ${ }^{54}$ Even though RepA interacts with RepC initiator protein and RepB' primase, neither of those two enzymes is related by sequence to either $E$. coli DnaA or DnaG primase. Our results indicate that RSF1010 RepA is not a good model for DnaB perhaps because it lacks an N-terminal interaction domain.

There is only one crystal structure of inhibitory myricetin bound to one of its targets phosphatidylinositol-3-kinase (PIK3) (1E90.pdb). ${ }^{55}$ Myricetin and 13 other flavonoids are low micromolar competitive inhibitors of PIK3, which is involved in signal transduction. ${ }^{56}$ Given that they inhibited with similar affinities, it was remarkable to find that every one of the five co-crystallized flavonoids adopted a different orientation within the PIK3 ATP site. For instance, myricetin bound at a different angle than the structurally similar quercetin (1E8W.pdb). Nevertheless, since the ATPase sites of RepA and DnaB are smaller than the ATP binding site of PIK3, it 
should be possible to design compounds that fit more snugly into their active sites.

New and emerging pathogenic bacteria and the rise in multi-drug-resistant bacterial strains are driving the need to discover novel antibiotics. Only a few DNA replication enzymes are targets for current antibiotics. Bacterial primase and DnaB helicase are novel targets that are beginning to generate lead compounds from among natural products. In future studies, we will use structural models of the DnaB helicase active site to help engineer myricetin's structure to improve its selectivity and strength.

\section{Materials and methods}

\subsection{Reagents}

The E. coli DnaB helicase and primase were expressed and purified as described. ${ }^{58,12}$ Ribonucleoside triphosphates (NTPs) were from Promega (Madison, WI). Myricetin, magnesium acetate, potassium glutamate, Hepes, and DTT were from Sigma (St. Louis, MO). Myricetin was dissolved in ethanol and its stock concentration determined using an extinction coefficient at $378 \mathrm{~nm}$ of $20,400 \mathrm{M}^{-1} \mathrm{~cm}^{-1} .59$ It was then diluted into DMSO for use in the experiments.

\subsection{Coupled ATPase assay}

ATP hydrolysis by E. coli DnaB was measured by an $\mathrm{NADH}$-coupled assay during which ATP was regenerated by the combined action of lactate dehydrogenase, pyruvate kinase, and their substrates. ${ }^{60,61}$ The regeneration reaction caused the loss of one NADH for every ATP hydrolyzed in the primary reaction, such that ATP remained constant while NADH declined according to the ATPase activity of DnaB. NADH was continuously monitored at its absorption maximum of $340 \mathrm{~nm}$, and its extinction coefficient plus stoichiometric factors were used to determine the moles ATP hydrolyzed per minute. The reaction buffer was $50 \mathrm{mM}$ Hepes, $100 \mathrm{mM}$ potassium glutamate, $\mathrm{pH}$ 7.5, $10 \mathrm{mM}$ DTT, $400 \mu \mathrm{M}$ NTPs, and $10 \mathrm{mM}$ magnesium acetate.

\subsection{Primer synthesis assay}

Thermally denaturing HPLC analysis was used to determine the size, composition, and quantity RNA primers synthesized as previously described. ${ }^{62}$ Briefly, RNA primer synthesis reactions were performed in $100 \mu$ l nuclease-free water reactions containing $50 \mathrm{mM}$ HEPES, $100 \mathrm{mM}$ potassium glutamate, $\mathrm{pH} 7.5,10 \mathrm{mM}$ DTT, $400 \mu \mathrm{M}$ NTPs, and $10 \mathrm{mM}$ magnesium acetate. DnaB helicase ( $800 \mathrm{nM}$ hexamer) and ssDNA template $(2 \mu \mathrm{M})$ were preincubated to the reaction temperature before the addition of primase $(2 \mu \mathrm{M})$. HPLC purified synthetic ssDNA 23-mer with the sequence 5'-d(CAGACAC ACACACACTGCACACA)-3' and with its 3 '-end blocked by a $\mathrm{C} 3$ linker was obtained from Integrated DNA Technologies (Coralville, IA). E. coli primase initiates from the d(CTG) tri- nucleotide underlined in the template sequence. After incubation at $30{ }^{\circ} \mathrm{C}$ for $1 \mathrm{~h}$, the samples were desalted through a Microspin G-25 column (Amersham, Piscataway, NJ) and then separated by thermally denaturing HPLC on a WAVE HPLC Nucleic Acid Fragment Analysis System with a DNASep HPLC column from Transgenomic (Omaha, NE).

\subsection{Data-fitting}

The data were fit to the indicated equations using Prism 4 for Macintosh (GraphPad Software, San Diego, CA).

\section{Acknowledgments}

This work was supported in part by a grant from the Department of Defense, Defense Advanced Research Program Agency (award W911NF0510275).

\section{References and notes}

1. M. A. Griep, Primase. In: S. Brenner and J. Miller, Editors, Encyclopedia of Genetics, Academic Press, New York (2001).

2. D. N. Frick and C. C. Richardson, Annu. Rev. Biochem. 70 (2001), p. 39.

3. M. A. Augustin, R. Huber, and J. T. Kaiser, Nat. Struct. Biol. 8 (2001), p. 57.

4. J. L. Keck and J. M. Berger, Nat. Struct. Biol. 8 (2001), p. 2.

5. M. Grompe, J. Versalovic, T. Koeuth, and J. R. Lupski, J. Bacteriol. 173 (1991), p. 1268.

6. J. Liu, M. Dehbi, G. Moeck, F. Arhin, P. Bauda, D. Bergeron, M. Callejo, V. Ferretti, N. Ha, T. Kwan, J. McCarty, R. Srikumar, D. Williams, J. J. Wu, P. Gros, J. Pelletier, and M. DuBow, Nat. Biotechnol. 22 (2004), p. 185.

7. Y. Zhang, F. D. Yang, Y. C. Kao, M. G. Kurilla, D. L. Pompliano, and I. B. Dicker, Anal. Biochem. 304 (2002), p. 174.

8. V. R. Hegde, H. Pu, M. Patel, T. Black, A. Soriano, W. Zhao, V.P. Gullo, and T.-M. Chan, Bioorg. Med. Chem. Lett. 14 (2004), p. 2275.

9. J. R. Swart and M. A. Griep, Biochemistry 34 (1995), p. 16097.

10. S. Khopde, E. E. Biswas, and S. B. Biswas, Biochemistry 41 (2002), p. 14820.

11. M. M. Stayton and A. Kornberg, J. Biol. Chem. 258 (1983), p. 13205.

12. S. K. Johnson, S. Bhattacharyya, and M. A. Griep, Biochemistry 39 (2000), p. 736.

13. S. Bhattacharyya and M. A. Griep, Biochemistry 39 (2000), p. 745.

14. K. Yoda and T. Okazaki, Mol. Gen. Genet. 227 (1991), p. 1.

15. P. M. Schaeffer, M. J. Headlam, and N. E. Dixon, IUBMB Life 57 (2005), p. 5.

16. F. Bonhoeffer and H. Schaller, Biochem. Biophys. Res. Commun. 20 (1965), p. 93.

17. F. Bonhoeffer, Z. Vererbungsl. 98 (1966), p. 141.

18. P. L. Carl, Mol. Gen. Genet. 109 (1970), p. 107.

19. R. A. Sclafani and J. A. Wechsler, J. Bacteriol. 146 (1981), p. 418. 
20. D. Saluja and G. N. Godson, J. Bacteriol. 177 (1995), p. 1104.

21. H. Masai, N. Nomura, and K. Arai, J. Biol. Chem. 265 (1990), p. 15134.

22. K. M. Carr and J. M. Kaguni, J. Biol. Chem. 277 (2002), p. 39815.

23. K. Tougu, H. Peng and K. J. Marians, J. Biol. Chem. 269 (1994), p. 4675 .

24. D. X. Gao and C. S. McHenry, J. Biol. Chem. 276 (2001), p. 4441.

25. M. E. Shea and H. Hiasa, J. Biol. Chem. 274 (1999), p. 22747.

26. M. Sivaraja, H. Giordano, and M. G. Peterson, Anal. Biochem. 265 (1998), p. 22.

27. D. L. Earnshaw and A. J. Pope, J. Biomol. Screening 6 (2001), p. 39.

28. S. Koepsell, S. Hanson, S. H. Hinrichs, and M.A. Griep, Anal. Biochem. 339 (2005), p. 353.

29. M. Chu, R. Mierzwa, L. Xu, L. He, J. Terracciano, M. Patel, V. Gullo, T. Black, W. Zhao, T. M. Chan, and A. T. McPhail, J. Nat. Prod. 66 (2003), p. 1527.

30. A. Agarwal, S. Louise-May, J. A. Thanassi, S. D. Podos, J. Cheng, C. Thoma, C. Liu, J. A. Wiles, D. M. Nelson, A. S. Phadke, B. J. Bradbury, M. S. Deshpande, and M. J. Pucci, Bioorg. Med. Chem. Lett. (2007), p. 2807.

31. H. Xu, G. Ziegelin, W. Schroder, J. Frank, S. Ayora, J. C. Alonso, E. Lanka, and W. Saenger, Nucleic Acids Res. 29 (2001), p. 5058.

32. G. A. McKay, R. Reddy, F. Arhin, A. Belley, D. Lehoux, G. Moeck, I. Sarmiento, T. R. Parr, P. Gros, J. Pelletier, and A. R. Far, Bioorg. Med. Chem. Lett. 16 (2006), p. 1286.

33. K. Leftheris, G. Ahmed, R. Chan, A. J. Dyckman, Z. Hussain, K. Ho, J. Hynes Jr., J. Letourneau, W. Li, S. Lin, A. Metzger, K. J. Moriarty, C. Riviello, Y. Shimshock, J. Wen, J. Wityak, S. T. Wrobleski, H. Wu, J. Wu, M. Desai, K. M. Gillooly, T. H. Lin, D. Loo, K. W. McIntyre, S. Pitt, D. R. Shen, D. J. Shuster, R. Zhang, D. Diller, A. Doweyko, J. Sack, J. Baldwin, J. Barrish, J. Dodd, I. Henderson, S. Kanner, G. L. Schieven, and M. Webb, J. Med. Chem. 47 (2004), p. 6283.

34. K. C. Ong and H. E. Khoo, Gen. Pharmacol. 29 (1997), p. 121.

35. T. P. Cushnie and A. J. Lamb, Int. J. Antimicrob. Agents 26 (2005), p. 343.

36. S. L. McGovern, E. Caselli, N. Grigorieff, and B. K. Shoichet, J. Med. Chem. 45 (2002), p. 1712.

37. S. L. McGovern, B. T. Helfand, B. Feng, and B. K. Shoichet, J. Med. Chem. 46 (2003), p. 4265.

38. K. Shinozuka, Y. Kikuchi, C. Nishino, A. Mori, and S. Tawata, Experientia 44 (1988), p. 882.

39. K. Ono, H. Nakane, M. Fukushima, J. C. Chermann, and F. Barre-Sinoussi, Eur. J. Biochem. 190 (1990), p. 469.

40. S. C. Chu, Y. S. Hsieh, and J. Y. Lin, J. Nat. Prod. 55 (1992), p. 179.
41. M. Menichincheri, D. Ballinari, A. Bargiotti, L. Bonomini, W. Ceccarelli, R. D'Alessio, A. Fretta, J. Moll, P. Polucci, C. Soncini, M. Tibolla, J. Y. Trosset, and E. Vanotti, J. Med. Chem. 47 (2004), p. 6466.

42. E. E. Biswas and S. B. Biswas, Biochemistry 38 (1999), p. 10929.

43. E. E. Biswas and S. B. Biswas, Biochemistry 38 (1999), p. 10919.

44. J. L. Keck, D. D. Roche, A. S. Lynch and J. M. Berger, Science 287 (2000), p. 2482.

45. M. Podobnik, P. McInerney, M. O'Donnell and J. Kuriyan, J. Mol. Biol. 300 (2000), p. 353.

46. S. A. Koepsell, M. A. Larson, M. A. Griep, and S. H. Hinrichs, J. Bacteriol. 188 (2006), p. 4673.

47. J. A. Ross and C. M. Kasum, Annu. Rev. Nutr. 22 (2002), p. 19.

48. J. Neuhard and P. Nygaard, Purines and Pyrimidines. In: F. C. Neihardt, Editor, Escherichia coli and Salmonella typhimurium: Cellular and Molecular Biology Vol. 1, American Society for Microbiology, Washington, DC (1987), p. 445.

49. S. S. Patel and K. M. Picha, Annu. Rev. Biochem. 69 (2000), p. 651.

50. W. Bujalowski and M. M. Klonowska, Biochemistry 32 (1993), p. 5888 .

51. J. C. Liao, Y. J. Jeong, D. E. Kim, S. S. Patel and G. Oster, J. Mol. Biol. 350 (2005), p. 452.

52. D. E. Rawlings and E. Tietze, Microbiol. Mol. Biol. Rev. 65 (2001), p. 481.

53. C. Weigel and H. Seitz, FEMS Microbiol. Rev. 30 (2006), p. 321.

54. J. Thirlway, I. J. Turner, C. T. Gibson, L. Gardiner, K. Brady, S. Allen, C. J. Roberts, and P. Soultanas, Nucleic Acids Res. 32 (2004), p. 2977.

55. E. H. Walker, M. E. Pacold, O. Perisic, L. Stephens, P. T. Hawkins, M. P. Wymann, and R. L. Williams, Mol. Cell 6 (2000), p. 909.

56. G. Agullo, L. Gamet-Payrastre, S. Manenti, C. Viala, C. Remesy, H. Chap and B. Payrastre, Biochem. Pharmacol. 53 (1997), p. 1649.

57. H. Xu, J. Frank, T. Niedenzu, and W. Saenger, Biochemistry 39 (2000), p. 12225.

58. M. A. Griep and E. R. Lokey, Biochemistry 35 (1996), p. 8260.

59. L. Mira, M. T. Fernandez, M. Santos, R. Rocha, M. H. Florencio, and K. R. Jennings, Free Radic. Res. 36 (2002), p. 1199.

60. J. Rosing, D. A. Harris, A. Kemp Jr., and E. C. Slater, Biochim. Biophys. Acta 376 (1975), p. 13.

61. D. A. Harris, Spectrophotometric Assays. In: D. A. Harris and C. L. Bashford, Editors, Spectrophotometry \& Spectrofluorimetry: A Practical Approach, IRL Press, Oxford (1988).

62. S. Koepsell, D. Bastola, S. H. Hinrichs, and M. A. Griep, Anal. Biochem. 332 (2004), p. 330. 